Article

\title{
Bonferroni Probabilistic Ordered Weighted Averaging Operators Applied to Agricultural Commodities' Price Analysis
}

\author{
Luis F. Espinoza-Audelo ${ }^{1}$, Maricruz Olazabal-Lugo ${ }^{1}$, Fabio Blanco-Mesa ${ }^{2}$, \\ Ernesto León-Castro ${ }^{3, *}$ and Victor Alfaro-Garcia ${ }^{4}$ (D) \\ 1 Universidad Autónoma de Occidente, Unidad Regional Culiacán, Culiacán 80200, Mexico; \\ luis.espinoza@udo.mx (L.F.E.-A.); maricruz.olazabal@udo.mx (M.O.-L.) \\ 2 Facultad de Ciencias Económicas y Administrativas, Escuela de Administración de Empresas, \\ Universidad Pedagógica y Tecnológica de Colombia, Tunja 150003, Colombia; fabio.blanco01@uptc.edu.co \\ 3 Faculty of Economics and Administrative Sciences, Universidad Católica de la Santísima Concepción, \\ Av. Alonso de Ribera 2850, Concepción 4030000, Chile \\ 4 Facultad de Contaduría y Ciencias Administrativas, Universidad Michoacana de San Nicolas de Hidalgo, \\ Gral. Francisco J. Múgica S/N, C.U., Morelia 58030, Mexico; victor.alfaro@umich.mx \\ * Correspondence: eleon@ucsc.cl
}

Received: 29 June 2020; Accepted: 8 August 2020; Published: 12 August 2020

\begin{abstract}
Financial markets have been characterized in recent years by their uncertainty and volatility. The price of assets is always changing so that the decisions made by consumers, producers, and governments about different products is not still accurate. In this situation, it is necessary to generate models that allow the incorporation of the knowledge and expectations of the markets and thus include in the results obtained not only the historical information, but also the present and future information. The present article introduces a new extension of the ordered weighted averaging (OWA) operator called the Bonferroni probabilistic ordered weighted average (B-POWA) operator. This operator is designed to unify in a single formulation the interrelation of the values given in a data set by the Bonferroni means and a weighted and probabilistic vector that models the attitudinal character, expectations, and knowledge of the decision-maker of a problem. The paper also studies the main characteristics and some families of the B-POWA operator. An illustrative example is also proposed to analyze the mathematical process of the operator. Finally, an application to corn price estimation designed to calculate the error between the price of an agricultural commodity using the B-POWA operator and a leading global market company is presented. The results show that the proposed operator exhibits a better general performance than the traditional methods.
\end{abstract}

Keywords: price forecasting; OWA operator; corn price; Bonferroni means; probabilistic operators

\section{Introduction}

Price analysis and prediction for agricultural commodities is a key element for decisionand policy-making [1], e.g., farmers require price analysis to accurately trade their stock [2], and governmental institutions rely on accurate price estimations to guarantee the favorable operation of the economy [3]. Therefore, the estimation of prices for the construction of different scenarios must be a corporate strategy when making short- and long-term plans [4], and when creating policies to promote appropriate programs for the development of the agricultural economy, food security, and coverage costs [5]. However, market volatility and fluctuations [6], along with the dynamic and systemic nature of the analyzed phenomena, make price analysis and prediction a highly complex task [5]. 
Among the diverse agricultural commodities in contemporary markets, corn is one of the most important. This agricultural commodity is present in multiple products and ranks as the third most cultivated product after wheat and rice [7]. According to the Food and Agriculture Organization of the United Nations (FAO) [8], corn's main purposes are human consumption and livestock nutrition. Other usages of this commodity are, e.g., biofuel production, plastics and medicines [9], and it is a basic ingredient in the production of more than 4000 items, including syrups, oils, flours, starches, juices, soft drinks, paints, toothpaste, paper, and cosmetics.

Accurate price analyses and forecasting is a long-pursued objective [10]. The latest developments in information technologies have created interesting approaches for the analysis and prediction of agricultural prices [11], including machine and deep learning models [3], multiple linear regression analyses [12], the vector error correction model and multi-output support vector regression [5], autoregressive integrated moving averages, partial least squares and artificial neural networks [13], and autoregressive integrated moving averages and Elman neural networks [14], among others. Some disadvantages of the traditional statistical techniques for price estimation include, e.g., the need for historical information and the inability to consider the expectations and knowledge of experts and decision-makers [15]. With this information, the research question of the paper is: how accurate is the forecasting price of an agricultural product based on aggregation operators? We hypothesize that using aggregation operations that include the knowledge and expectations of the decision-makers or experts in the problem can improve the accuracy of forecasting instead of traditional formulations based only on historical data.

The rapid advancements produced in recent decades in computer science and intelligent and expert systems [16] have proven to be effective when analyzing data from different sources and producing unified information. One of these advancements is the ordered weighted average (OWA) operator developed by Yager in 1988 [17] being $\mathrm{f}$ the most cited paper about aggregation operators [18]. The main idea of this operator is to aggregate information using a weighting vector and reordering mechanism according to different criteria and the attitudinal character of the decision-maker. Since the appearance of the OWA operator, many extensions have been proposed, including logarithmic averaging operators [19-21], moving averages [22-24] and Bonferroni means [25,26]. These developments have been applied to diverse fields, such as decision sciences [27,28], finance [29,30], and policy decision-making [31,32]. Moreover, multiple extensions have been developed using the Bonferroni OWA operator, which have been diversified with distance measures applied to problems in personnel selection [33,34], induced variables applied to forecast and business risk management $[35,36]$ and extensions with central tendency measures such as variance and covariance $[37,38]$.

The aim of this paper is to introduce an extension of the OWA operator that combines Bonferroni means [39] and probabilistic vectors [40,41], named the Bonferroni probabilistic ordered weighted average (B-POWA) operator. The contribution of this new operator is that in one formulation the interrelation of the arguments can be used with the use of the Bonferroni means and also includes probabilistic uncertainty theory with the use of the weighting vector and probabilistic vector; with these three components it is possible to add different qualitative information to the formulation, and with that new present possible scenarios based on the expectations of the decision-maker. The design also includes the reordering step of the OWA operator. Additionally, the main characteristics and properties of the newly introduced operator are studied and presented. The novelty of this paper is in two ways: the first one is the presentation of a new aggregation operator that combines Bonferroni means, OWA operators and probabilities, and the second is the solution of forecasting agricultural commodities by the presentation of a step-by-step process; with these it is possible to replicate the methodology to different problems that have similar elements and attributes.

The remainder of the paper proceeds as follows. Section 2 presents the preliminaries and foundations of the B-POWA operator. Section 3 introduces the B-POWA operator and its main characteristics and properties. Section 4 presents a mathematical example of the operator. Section 5 
presents price forecasting using the B-POWA operator. Finally, Section 6 summarizes and concludes the paper.

\section{Preliminaries}

In this section, the basic definitions are presented for the development of the paper, including the ordered weighted average (OWA) operators, Bonferroni operators, and some of their extensions.

The Bonferroni mean, since its creation by [39], has had different applications, such as multiple significance tests applied in medicine [42], genetic differentiations of two or more collections of samples [43], wear behavior in parts with micromechanical properties and characteristics [44], and multicriteria decision-making [36], among other areas of knowledge.

The great diversity of the problems at hand forces decision-makers to look for new methods that allow them to broaden their expectations and model them in different scenarios. Bonferroni [39] proposed an operator for multiple aggregate criteria that uses the product of the means of two criteria $a_{i}$ and $a_{j}$, thereby capturing the interrelation between the arguments. This operation is performed to implement satisfaction criteria [27]. By rearranging the terms [26], it can also be formulated in the following way:

$$
\mathrm{B}\left(\mathrm{a}_{1}, \mathrm{a}_{2}, \ldots, \mathrm{a}_{\mathrm{n}}\right)=\left(\sum_{\mathrm{k}=1}^{\mathrm{n}} \mathrm{a}_{\mathrm{k}}^{\mathrm{r}}\left(\frac{1}{1-\mathrm{n}} \sum_{\mathrm{j}=1 ; \mathrm{j} \neq \mathrm{k}}^{\mathrm{n}} \mathrm{a}_{\mathrm{j}}^{\mathrm{q}}\right)\right)^{\frac{1}{\mathrm{r}+\mathrm{q}}},
$$

where $r$ and $q$ are parameters such that $r, q \geq 0$ and the arguments $\mathrm{a} \geq 0$.

There are several ways to add information for decision-making; one such method is the ordered weighted average (OWA) [17]. The advantage of this methodology is that by rearranging the weights and criteria, it is possible to obtain results according to the expectations of the decision-maker, which can overvalue or undervalue the results.

Using Bonferroni Means (BM), numerous applications have been developed, as highlighted by the OWA operator extension presented by [26] and called the Bonferroni OWA operator.

Definition 1. Let $W$ be an OWA weighting vector of dimension $n-1$ with components $w_{i} \in[0,1]$ when $\sum_{i} w_{i}=1$. Then, we can define this aggregation as $O W A_{W}\left(V^{i}\right)=\left(\sum_{j=1}^{n-1} w_{i} a_{\pi_{k}(j)}\right)$, where $a_{\pi_{k}(j)}$ is the largest element in the $n-1$ tuple $V^{i}=\left(a_{1}, \ldots, a_{i-1}, a_{i+1}, \ldots, a_{n}\right)$. The Bonferroni OWA is a mean-type aggregation operator. It can be defined by using the following expression.

$$
B-\operatorname{OWA}\left(a_{1}, \ldots, a_{n}\right)=\left(\frac{1}{n} \sum_{i} a_{i}^{r} O_{W A}\left(V^{i}\right)\right)^{\frac{1}{r+q}},
$$

where $\left(V^{i}\right)$ is the vector of all $a_{j}$ except $a_{i}$.

Definition 2. An OWA operator of dimension $n$ is a mapping $O W A: R^{n} \rightarrow R$ associated with a weight vector $W$ of dimension $n$ such that $\sum_{j=1}^{n} w_{j}=1$ and $w_{j} \in[0,1]$ according to the following formula:

$$
\operatorname{OWA}\left(\mathrm{a}_{1}, \mathrm{a}_{2}, \ldots, \mathrm{a}_{\mathrm{n}}\right)=\sum_{\mathrm{j}=1}^{\mathrm{n}} \mathrm{w}_{\mathrm{j}} \mathrm{b}_{\mathrm{j}}
$$

where $b_{j}$ is the jth major element of the $a_{i}$ collection.

Note that if $w_{i}=\frac{1}{n-1}$ for all $i, \operatorname{OWA}_{W}\left(V^{i}\right)=\left(\frac{1}{n-1} \sum_{j=1 ; j \neq i}^{n} a_{j}^{q}\right)$, and Equation (2) becomes the classical Bonferroni mean. 
Definition 3. A probabilistic ordered weighted average (POWA) operator is a POWA merger: POWA : $R^{n} \rightarrow R$ of dimension $n$ has a weighting vector $W$ associated with $\sum_{j=1}^{n} w_{j}=1$ and $w_{j} \in[0,1]$. The formulation is as follows:

$$
\operatorname{POWA}\left(\mathrm{a}_{1}, \ldots, \mathrm{a}_{\mathrm{n}}\right)=\sum_{\mathrm{j}=1}^{\mathrm{n}} \mathrm{V}_{\mathrm{j}} \mathrm{b}_{\mathrm{j}}
$$

where $b_{j}$ is the $j$ th largest of the $a_{i}$, each argument $a_{i}$ has an associated probability $V_{i}$ with $\sum_{i=1}^{n} V_{i}=1$ and $v_{i} \in[0,1], v_{j}=\beta w_{j}+(1-\beta) v_{j}$ with $\beta \in[0,1]$ and $v_{j}$ is the probability $v_{i}$ ordered according to $b_{j}$.

\section{The Bonferroni POWA Operator and Its Extensions}

The objective of this paper is to present an extension of the OWA operator called the Bonferroni probabilistic ordered weighted average (B-POWA) operator. This operator makes it possible to sort information within a maximum and a minimum, unifying by means of vectors of weights $\mathrm{W}_{\mathrm{i}}$ considered by the degree of importance for decision-makers, and the probability $\mathrm{p}_{\mathrm{i}}$ in the same formulation. It can be defined as follows:

Proposition 1. B-POWA is a probabilistic mean-type aggregation operator associated with $w_{j}$ in the vector $W$ with $\sum_{j=1}^{n} w_{j}=1$ and $w_{j} \in[0,1]$ and a probability $p_{i}$ of the vector $P$ with $\sum_{i=1}^{n} p_{i}=1$ and $p_{i} \in[0,1]$. Let $L_{w_{j}}$ be an aggregation vector of the weighting factor and the probabilities for $a_{i} \neq a_{j}$ such that $L_{w_{j}}=$ $\beta\left(w_{j} b_{j}^{q}\right)+(1-\beta)\left(p_{j} b_{j}^{q}\right)$, where $p_{j}$ is the probability ordered according to $b_{j}$, according to the jth largest of the $a_{i}$. The values $r$ and $q$ are the degrees of the multiple averages that the double mean generalizes by adjusting the confidence level of each of the intervals $a_{i}$ and $a_{j}$. The B-POWA is defined by using the following expression.

$$
\mathrm{B}-\mathrm{POWA}=\left(\frac{1}{\mathrm{n}} \sum_{\mathrm{i}=1}^{\mathrm{n}} \sum_{\mathrm{j}=1}^{\mathrm{n}-1} \mathrm{a}_{\mathrm{i}}^{\mathrm{r}} \mathrm{L}_{\mathrm{w}_{\mathrm{j}}}\right)^{\frac{1}{\mathrm{r}+\mathrm{q}}}
$$

where $L_{w_{j}}$ is the vector of all $a_{j}$ except $a_{i}$.

In addition to the OWA aggregation and the probabilities of the arguments, this new operator allows multiple comparisons between the inputs and captures their interrelation. Thus, when $\beta=0$, we have the aggregation of the probabilities of the arguments $a_{i} \neq a_{j}$, and with $\beta=1$, the operator excludes the comparison argument. The above formulation of Proposition 1 can also be expressed as follows:

Let $W$ be the weight vector $w_{j}$ of dimension $n$ with components $w_{j} \in[0,1]$ when $\sum_{j=1}^{n} w_{j}=1$. Therefore, we can define this aggregation as $\operatorname{OWA}_{w}\left(V^{i}\right)=\sum_{j=1}^{n-1} W_{j} a_{\pi_{i}(j)}{ }^{\prime}$, where $a_{\pi_{i}(j)}^{q}$ is the jth element of the tuple $\mathrm{V}^{\mathrm{i}}$. In the part corresponding to the probabilities, we have $\mathrm{PA}_{\mathrm{w}_{\mathrm{j}}}$, which is the aggregation of the probabilities of the arguments ordered according to $b_{j}$ and with $a_{j} \neq a_{i}$ being $\operatorname{PA}_{w_{j}}=\sum_{j=1}^{n-1} p_{j} b_{j}^{q}$, where $\sum_{i=1}^{n} p_{i}=1$ and $p_{i} \in[0,1]$.

$$
\operatorname{B}-\operatorname{POWA}\left(\mathrm{a}_{1}, \mathrm{a}_{2}, \ldots, \mathrm{a}_{\mathrm{n}}\right)=\beta\left(\frac{1}{\mathrm{n}} \sum_{\mathrm{i}=1}^{\mathrm{n}} \mathrm{a}_{\mathrm{i}}^{\mathrm{r}} \mathrm{OWA}_{W}\left(\mathrm{~V}^{\mathrm{i}}\right)\right)^{\frac{1}{\mathrm{r}+\mathrm{q}}}+(1-\beta)\left(\frac{1}{\mathrm{n}} \sum_{\mathrm{i}=1}^{\mathrm{n}} \mathrm{a}_{\mathrm{i}}^{\mathrm{r}} \mathrm{PA}_{\mathrm{W}_{\mathrm{j}}}\right)^{\frac{1}{\mathrm{r}+\mathrm{q}}},
$$

where $\left(V^{i}\right)$ is the tuple of all $a_{j} \neq a_{i}$ as $\left(a_{1}, \ldots, a_{i-1}, a_{i+1}, \ldots, a_{n}\right)$.

Note that when $\beta=0$, Bonferroni Probabilistic (B-PO) is strictly obtained, and its formulation is as follows:

$$
B-P O\left(a_{1}, a_{2}, \ldots, a_{n}\right)=\left(\frac{1}{n} \sum_{i} a_{i}^{r} P A_{w_{j}}\right)^{\frac{1}{r+q}},
$$

where $P A_{w_{j}}$ is the aggregation of the probabilities of the arguments ordered by $b_{j}$ and with $a_{j} \neq a_{i}$, where $P A_{w_{j}}=\sum_{j=1}^{n-1} p_{j} b_{j}$, and where $\sum_{i=1}^{n} p_{i}=1$ and $p_{i} \in[0,1]$. The values $r$ and $q$ are the degrees of 
the multiple averages that the double mean generalizes by adjusting the confidence level of each of the intervals $a_{i}$ and $a_{j}$.

Additionally, if $\beta=1$, the B-OWA operator is strictly obtained. Now, with respect to the value of $a_{i}$, if all $a_{i}=0, B-$ POWA $(0, \ldots, 0)=0$ is obtained. When $a_{i}=1$, then $B-\operatorname{POWA}(1, \ldots, 1)=$ $\beta\left(\frac{1}{n} \sum_{i} O_{W A}\left(V^{i}\right)\right)^{\frac{1}{r+q}}+(1-\beta)\left(\frac{1}{n} \sum_{i} P_{W_{j}}\right)^{\frac{1}{r+q}}$. Here, one should consider that $V^{i}$ is the tuple of the $a_{j} \neq a_{i}$ and will, therefore, have a value of one, giving the property of idempotence to the operator, BON - POWA $(1, \ldots, 1)=1$.

Another property that the B-POWA operator has is monotonicity. If one has $c_{i} \geq a_{i}$, and if one considers B - POWA $\left(a_{1}, a_{2}, \ldots, a_{n}\right)$ and B - POWA $\left(c_{1}, c_{2}, \ldots, c_{n}\right)$, then given this, under this property of the operator, OWA $\left(a_{1}, a_{2}, \ldots, a_{i-1}, a_{i+1}, \ldots, a_{n}\right) \leq \operatorname{OWA}_{W}\left(c_{1}, c_{2}, \ldots, c_{i-1}, c_{i+1}, \ldots, c_{n}\right)$, and therefore, B - POWA $\left(a_{1}, a_{2}, \ldots, a_{n}\right) \leq B-$ POWA $\left(c_{1}, c_{2}, \ldots, c_{n}\right)$.

In addition, from the previous situation, considering the delimitation if $\mathrm{a}^{*}=$ $\operatorname{Max}_{\mathrm{i}}\left[\mathrm{a}_{\mathrm{i}}\right], \mathrm{B}-\operatorname{POWA}\left(\mathrm{a}_{1}, \mathrm{a}_{2}, \ldots, \mathrm{a}_{\mathrm{n}}\right) \leq \mathrm{B}-\operatorname{POWA}\left(\mathrm{a}^{*}, \ldots, \mathrm{a}^{*}\right)=\mathrm{a}^{*}$ and, if $\mathrm{a}_{*}=\operatorname{Min}_{\mathrm{i}}\left[\mathrm{a}_{\mathrm{i}}\right]$, then $B-\operatorname{POWA}\left(a_{1}, a_{2}, \ldots, a_{n}\right) \geq B$ - POWA $\left(a_{*}, \ldots, a_{*}\right)=a_{*}$. Therefore, $\operatorname{Min}_{i}\left[a_{i}\right] \leq B-$ POWA $\left(a_{1}, a_{2}, \ldots, a_{n}\right) \leq \operatorname{Max}_{i}\left[a_{i}\right]$. From this, it is necessary that the operator $B-$ POWA provides a media class as an aggregation operator.

\section{Special Cases of the B-POWA Operator}

Some special cases are presented according to the values that $\mathrm{W}$ takes. Consider the situation where $\mathrm{W}=\mathrm{W}^{*}$; here, for $\mathrm{k}=2$ to $\mathrm{n}-1, \mathrm{w}_{1}=1$ and $\mathrm{w}_{\mathrm{k}}=0$, thus obtaining a B-POWA with the maximum of $\left(\mathrm{V}^{\mathrm{i}}\right)$ :

$$
B-\operatorname{POWA}_{W^{*}}\left(a_{1}, a_{2}, \ldots, a_{n}\right)=\beta\left(\frac{1}{n} \sum_{i=1}^{n} a_{i}^{r} \operatorname{Max}\left(V^{i}\right)\right)^{\frac{1}{r+q}}+(1-\beta)\left(\frac{1}{n} \sum_{i=1}^{n} a_{i}^{r} P_{W_{j}}\right)^{\frac{1}{r+q}},
$$

Now, $\operatorname{Max}\left(\mathrm{V}^{\mathrm{i}}\right)$ corresponds to the largest element of a with $\mathrm{i} \neq \mathrm{j}$. Additionally, let $\mathrm{a}_{\text {ind }(\mathrm{j})}$ be the $j$-th largest element of $a_{i}$, so for $i \neq \operatorname{ind}(1)$, one must have $\operatorname{Max}\left(V^{i}\right)=a_{\text {ind }(1)}$, and therefore, $\operatorname{Max}\left(\mathrm{V}^{\mathrm{i}}\right)=\mathrm{a}_{\text {ind }(1)}=\operatorname{Max}_{\mathrm{i}}\left[\mathrm{a}_{\mathrm{i}}\right]$. Now, for $\mathrm{i}=\operatorname{ind}(1)$, then $\operatorname{Max}\left(\mathrm{V}^{\mathrm{i}}\right)=\mathrm{a}_{\text {ind }(2)}$. With values $\mathrm{r}=\mathrm{q}=1$, substituting in Equation (8),

$$
\begin{aligned}
& \text { B-POWA }_{W^{*}}\left(a_{1}, a_{2}, \ldots, a_{n}\right)=\beta\left(\frac{1}{n} \sum_{i=1}^{n} a_{\text {ind }(j)}\left(a_{\text {ind }(1)}\right)+a_{\text {ind }(1)}\left(a_{\text {ind }(2)}\right)\right)^{\frac{1}{2}}+ \\
& (1-\beta)\left(\frac{1}{n} \sum_{\mathrm{i}=1}^{\mathrm{n}} \mathrm{a}_{\mathrm{i}} \mathrm{PA}_{\mathrm{w}_{\mathrm{j}}}\right)^{\frac{1}{2}}=\beta\left(\frac{1}{\mathrm{n}}\left(\mathrm{a}_{\mathrm{ind}(1)} \sum_{\mathrm{i}=1}^{\mathrm{n}} \mathrm{a}_{\mathrm{ind}(\mathrm{j})}+\mathrm{a}_{\mathrm{ind}(2)}\right)\right)^{\frac{1}{2}}+ \\
& (1-\beta)\left(\frac{1}{n} \sum_{i=1}^{n} a_{i} P_{w_{j}}\right)^{\frac{1}{2}} \text {, } \\
& \mathrm{B}-\operatorname{POWA}_{\mathrm{W}^{*}}\left(\mathrm{a}_{1}, \mathrm{a}_{2}, \ldots, \mathrm{a}_{\mathrm{n}}\right)=\beta\left(\mathrm{a}_{\text {ind }(1)}\left(\frac{1}{\mathrm{n}} \sum_{\mathrm{i}=1}^{\mathrm{n}} \mathrm{a}_{\text {ind }(\mathrm{j})}-\left(\mathrm{a}_{\text {ind }(1)}-\mathrm{a}_{\text {ind }(2)}\right)\right)\right)^{\frac{1}{2}}+ \\
& (1-\beta)\left(\frac{1}{n} \sum_{i=1}^{n} a_{i} P_{w_{j}}\right)^{\frac{1}{2}} \text {, } \\
& B-\operatorname{POWA}_{W^{*}}\left(a_{1}, a_{2}, \ldots, a_{n}\right) \approx \beta\left(\operatorname{Max}_{i}\left[a_{i}\right] * \operatorname{average}\left(a_{1}, a_{2}, \ldots, a_{n}\right)\right)^{\frac{1}{2}}+ \\
& (1-\beta)\left(\frac{1}{n} \sum_{\mathrm{i}=1}^{\mathrm{n}} \mathrm{a}_{\mathrm{i}} \mathrm{PA}_{\mathrm{w}_{\mathrm{j}}}\right)^{\frac{1}{2}} .
\end{aligned}
$$

In the case of $\mathrm{W}=\mathrm{W}^{*}$ with $\mathrm{w}_{\mathrm{n}-1}=1$ and $\mathrm{w}_{\mathrm{k}}=0$ for $\mathrm{k}=1$ to $\mathrm{n}-2$, there is a minimum B-POWA,

$$
B-\operatorname{POWA}_{W_{*}}\left(a_{1}, a_{2}, \ldots, a_{n}\right)=\beta\left(\frac{1}{n} \sum_{i=1}^{n} a_{i}^{r} \operatorname{Min}\left(V^{i}\right)\right)^{\frac{1}{r+q}}+(1-\beta)\left(\frac{1}{n} \sum_{i=1}^{n} a_{i}^{r} P_{W_{j}}\right)^{\frac{1}{r+q}},
$$

where $\operatorname{Min}\left(V^{i}\right)$ is the smallest element of a with $i \neq j$. Additionally, let $a_{\text {ind }(j)}$ be the $j$-th smallest element of $a_{i}$, so for $i \neq \operatorname{ind}(n)$ one must have $\operatorname{Min}\left(V^{i}\right)=a_{\text {ind }(n)}$, and therefore, $\operatorname{Min}\left(V^{i}\right)=a_{\text {ind }(n)}=\operatorname{Min}_{i}\left[a_{i}\right]$. 
Now, for $\mathrm{i}=\operatorname{ind}(\mathrm{n})$ then the $\operatorname{Min}\left(\mathrm{V}^{\mathrm{i}}\right)=\mathrm{a}_{\text {ind(n-1) }}$. Following the algebraic operations of the previous case, with values $r=q=1$, one obtains:

$$
\begin{gathered}
B-\operatorname{POWA}_{W_{*}}\left(a_{1}, a_{2}, \ldots, a_{n}\right) \approx \beta\left(\operatorname{Min}_{i}\left[a_{i}\right] * \operatorname{average}\left(a_{1}, a_{2}, \ldots, a_{n}\right)\right)^{\frac{1}{2}}+ \\
(1-\beta)\left(\frac{1}{n} \sum_{i=1}^{n} a_{i} P_{w_{j}}\right)^{\frac{1}{2}} .
\end{gathered}
$$

To determine the weight vector, there are different approaches developed in the literature $[45,46]$. Some measures to consider are the dispersion, the balance operator, the divergence of $\mathrm{W}$ and the degree of orness. These are defined as follows:

Dispersion is the measure of the degree to which $\mathrm{w}$ takes into account the information in the arguments during aggregation [45]. This measure of dispersion uses the Shannon information concept, i.e., the more dispersed $\mathrm{w}$ is, the more information about the individual criteria is being used in the aggregation process [17], and it is defined as:

$$
\mathrm{H}(\mathrm{W})=-\sum_{\mathrm{i}=1}^{\mathrm{n}} \mathrm{w}_{\mathrm{i}} \ln \mathrm{w}_{\mathrm{i}}
$$

for the B-POWA, the entropy is

$$
\mathrm{H}(\mathrm{W})=\beta\left(-\left(\frac{1}{\mathrm{n}} \sum_{\mathrm{i}=1}^{\mathrm{n}} \ln \mathrm{w}_{\mathrm{i}}\left(\begin{array}{c}
\sum_{\mathrm{j}=1}^{\mathrm{n}} \mathrm{w}_{\mathrm{j}} \ln \mathrm{w}_{\mathrm{j}} \\
\mathrm{i} \neq \mathrm{j}
\end{array}\right)\right)^{\frac{1}{\mathrm{r}+\mathrm{q}}}\right)+(1-\beta)\left(\frac{1}{\mathrm{n}} \sum_{\mathrm{i}=1}^{\mathrm{n}} \mathrm{a}_{\mathrm{i}}^{\mathrm{r}} \mathrm{PA}_{\mathrm{w}_{\mathrm{j}}}\right)^{\frac{1}{\mathrm{r}+\mathrm{q}}} .
$$

The degree of orness is associated with the weighting function [17] and characterizes the degree to which the aggregation is like an orness operation [45] it is defined as

$$
\operatorname{orness}(\mathrm{W})=\frac{1}{\mathrm{n}-1} \sum_{\mathrm{i}=1}^{\mathrm{n}}(\mathrm{n}-\mathrm{i}) \mathrm{w}_{\mathrm{i}}
$$

the degree of orness for the B-POWA is obtained from:

$$
\operatorname{orness}(W)=\beta\left(\frac{1}{n} \sum_{i=1}^{n}\left(\frac{n-i}{n-1}\right)\left(\sum_{\substack{j=1 \\ i \neq j}}^{n}\left(\frac{n-j}{n-1}\right) w_{j}\right)\right)^{\frac{1}{r+q}}+(1-\beta)\left(\frac{1}{n} \sum_{i=1}^{n} a_{i}^{r} P A_{w_{j}}\right)^{\frac{1}{r+q}} .
$$

Thus, the divergence of $\mathrm{W}$ is obtained. The degree of divergence allows a useful measure to be obtained when the dispersion or attitudinal character is incomplete [47,48]:

$$
\begin{aligned}
& \operatorname{Div}(W)=\beta\left(\frac{1}{n} \sum_{i=1}^{n}\left(\frac{n-i}{n-1}-\operatorname{orness}(W)\right)^{2}\left(\sum_{\substack{j=1 \\
i \neq j}}^{n}\left(\frac{n-j}{n-1}-\operatorname{orness}(W)\right)^{2} w_{j}\right)\right)^{\frac{1}{r+q}}+ \\
& (1-\beta)\left(\frac{1}{n} \sum_{i=1}^{n} a_{i}^{r} P_{w_{j}}\right)^{\frac{1}{r+q}} .
\end{aligned}
$$

The balance operator allows for the measurement of its degree of balance between favoring the higher-valued elements or lower-valued elements [49], i.e., it measures the balance of the weights against the orness or the andness [50] for the B-POWA results from:

$$
\operatorname{Bal}(W)=\beta\left(\frac{1}{n} \sum_{i=1}^{n}\left(\frac{n+1-2_{i}}{n-1}\right)\left(\sum_{\substack{j=1 \\ i \neq j}}^{n}\left(\frac{n+1-2_{j}}{n-1}\right) w_{j}\right)\right)^{\frac{1}{r+q}}+(1-\beta)\left(\frac{1}{n} \sum_{i=1}^{n} a_{i}^{r} P A_{w_{j}}\right)^{\frac{1}{r+q}}
$$


Therefore, if $\mathrm{q}=0$, then B-POWA would be:

$$
\begin{aligned}
& \mathrm{B}-\operatorname{POWA}^{\mathrm{r}, 0}\left(\mathrm{a}_{1}, \mathrm{a}_{2}, \ldots, \mathrm{a}_{\mathrm{n}}\right)=\beta\left(\frac{1}{\mathrm{n}} \sum_{\mathrm{i}=1}^{\mathrm{n}} \mathrm{a}_{\mathrm{i}}^{\mathrm{r} O W A_{W}}\left(\mathrm{~V}^{\mathrm{i}}\right)\right)^{\frac{1}{\mathrm{r}+0}}+ \\
& (1-\beta)\left(\frac{1}{n} \sum_{i=1}^{n} a_{i}^{r} P A_{w_{j}}\right)^{\frac{1}{r+0}}=\beta\left(\frac{1}{n} \sum_{i=1}^{n} a_{i}^{r}\right)^{\frac{1}{r}}+(1-\beta)\left(\frac{1}{n} \sum_{i=1}^{n} a_{i}^{r}\right)^{\frac{1}{r}} \\
& =\left(\frac{1}{n} \sum_{i=1}^{n} a_{i}^{r}\right)^{\frac{1}{r}}(\beta+1-\beta)=\left(\frac{1}{n} \sum_{i=1}^{n} a_{i}^{r}\right)^{\frac{1}{r}}
\end{aligned}
$$

If $\mathrm{r}=1$ and $\mathrm{q}=0$, substituting in Equation (13), B-POWA is reduced to an average:

$$
B-\operatorname{POWA}^{1,0}\left(a_{1}, a_{2}, \ldots, a_{n}\right)=\frac{1}{n} \sum_{i=1}^{n} a_{i} .
$$

If $\mathrm{r}=2$ and $\mathrm{q}=0$, then the B-POWA is reduced to a quadratic mean, which is obtained by substituting in Equation (13) as follows:

$$
\mathrm{B}-\operatorname{POWA}^{2,0}\left(\mathrm{a}_{1}, \mathrm{a}_{2}, \ldots, \mathrm{a}_{\mathrm{n}}\right)=\left(\frac{1}{\mathrm{n}} \sum_{\mathrm{i}=1}^{\mathrm{n}} \mathrm{a}_{\mathrm{i}}^{2}\right)^{\frac{1}{2}}=\sqrt{\frac{1}{\mathrm{n}} \sum_{\mathrm{i}=1}^{\mathrm{n}} \mathrm{a}_{\mathrm{i}}^{2}} .
$$

If $\mathrm{r} \rightarrow+\infty$ and $\mathrm{q}=0$, substituting in Equation (13), the B-POWA is reduced to the MAX operator, that is, the maximum value in the arguments $\mathrm{a}_{\mathrm{i}}$ :

$$
\lim _{r \rightarrow+\infty} B-\operatorname{POWA}^{r, 0}\left(a_{1}, a_{2}, \ldots, a_{n}\right)=\left(\frac{1}{n} \sum_{i=1}^{n} a_{i}^{r}\right)^{\frac{1}{r}}=\left(\frac{1}{n} \sum_{i=1}^{n} a_{i}^{\infty}\right)^{\frac{1}{\infty}}=\frac{1}{n} \sum_{i=1}^{n} a_{i}^{\frac{\infty}{\infty}}=\max \left\{a_{i}\right\}
$$

If $\mathrm{r} \rightarrow 0$ and $\mathrm{q}=0$, substituting in Equation (13), B-POWA is reduced to the geometric mean:

$$
\begin{aligned}
\lim _{r \rightarrow 0} B-\operatorname{POWA}^{r, 0}\left(a_{1}, a_{2}, \ldots, a_{n}\right)= & \left(\frac{1}{n} \sum_{i=1}^{n} a_{i}^{r}\right)^{\frac{1}{r}}=\left[\left(\prod_{i=1}^{n} a_{i}^{r}\right)^{\frac{1}{n}}\right]^{\frac{1}{r}}=\left(\prod_{i=1}^{n} a_{i}\right)^{\frac{r}{n r}}= \\
& \left(\prod_{i=1}^{n} a_{i}\right)^{\frac{1}{n}} .
\end{aligned}
$$

If $\mathrm{r}=\mathrm{q}=1$, substituting in Equation (7), the reduced expression for the B-POWA from Equation (6) is obtained:

$$
\begin{gathered}
B-P O W A=\frac{1}{n}\left(\beta\left(\sum_{i=1}^{n} a_{i} O W A_{W}\left(V^{i}\right)\right)^{\frac{1}{2}}+(1-\beta)\left(\sum_{i=1}^{n} a_{i}^{r} P_{w_{j}}\right)^{\frac{1}{2}}\right)= \\
\left(\frac{1}{n} \sum_{i=1}^{n} \sum_{j=1}^{n-1} a_{i} L_{W_{j}}\right)^{\frac{1}{2}} .
\end{gathered}
$$

In addition, it is important to note that this extension reflects a solution to the subjective probability that includes degrees of importance that can be assigned to the data during processing by capturing continuous aggregations and multiple relationships. These problems are caused by the unavailability of sufficient information to establish an objective probability, even if the most important beliefs [40], criteria, and circumstances are available when the meaning of the information is more relevant than its own measurement [51]. In this sense, the aggregate and continuously related subjective probabilities are represented in Equation (6), where the values of $\beta$ and $(1-\beta)$ are the degree of importance of the aggregation operator.

\section{Mathematical Example}

To understand the application of this new operator, the following example is proposed:

A company needs to manufacture a new product upon request for one of its largest customers. Manufacturing requires an agricultural input that can be acquired in four different areas of the country. However, suppliers have stated that they cannot ensure a compliant delivery since it depends on 
climatic factors and pests, and there is no method that improves the yield of the crop. The company will assume the loss of noncompliant agricultural input in lots of 100 tons.

Thus, there are five possible states of nature in which a greater number of acceptable tons can result in a lower yield in the tonnage that can be used by the company. Each of these scenarios has an associated probability, as well as an assessment given by experts.

Step 1: The payment table is constructed and indicates the number of acceptable tons that each zone supplier delivers according to the varied states of nature. The information is as follows (See Table 1):

Table 1. Tons of each supplier.

\begin{tabular}{llllll}
\hline & $\mathbf{S}_{\mathbf{1}}$ & $\mathbf{S}_{\mathbf{2}}$ & $\mathbf{S}_{\mathbf{3}}$ & $\mathbf{S}_{\mathbf{4}}$ & $\mathbf{S}_{\mathbf{5}}$ \\
\hline $\mathbf{P}_{\mathbf{1}}$ & 90 & 85 & 80 & 78 & 60 \\
$\mathbf{P}_{\mathbf{2}}$ & 70 & 68 & 62 & 55 & 50 \\
$\mathbf{P}_{\mathbf{3}}$ & 80 & 75 & 70 & 70 & 60 \\
$\mathbf{P}_{\mathbf{4}}$ & 60 & 65 & 50 & 48 & 40 \\
\hline
\end{tabular}

Step 2: Based on the assessment given by experts, as well as known information from previous events, weight vectors are determined $W_{i}=\{0.3,0.25,0.15,0.2,0.1\}$ and probability $P_{i}=\{0.1,0.2,0.4,0.2,0.1\}$ for the states of nature $S=\left\{S \_1, S \_2, S \_3, S \_4, S \_5\right\}$, respectively. For this example, the degrees of the multiple averages $r$ and $q$ are considered equal to 1 .

Step 3: Vectors $V^{i}$ are established that allow us to calculate the $O W A_{W}$ for $a_{j} \neq a_{i}$, that is, the $\operatorname{Pr}_{i} S_{j}$ pairs. A case applied to Provider 1 in all vectors can be seen in Appendix A.1.

Step 4: With the vectors $V^{i}$ for all suppliers, we proceed to calculate the value of $\operatorname{OWA}_{W}\left(V^{i}\right)$ from the exclusive alternatives of $a_{i}$ multiplied by the weight vector $W$ (see Appendix A.2).

Step 5: The previous results are multiplied by the payment to each supplier in a state of nature $\left(\operatorname{Pr}_{\mathrm{i}} \mathrm{S}_{\mathrm{j}}\right)$ and the sum is divided by the number of arguments and raised to the quotient between 1 and the sum of $r$ and q. For Provider 1, see Appendix A.3.

Note that the above corresponds to a B-OWA that is constitutive of the B-POWA.

Step 6: To complete the calculation of the B-POWA, it is necessary to determine the value of the added probability $\mathrm{PA}_{\mathrm{W}_{\mathrm{j}}}$, obtained from the multiplication of the vector $\mathrm{V}^{\mathrm{i}}$ by the probability $\mathrm{p}_{\mathrm{j}}$ ordered according to $b_{j}$. For the case being shown, see Appendix A.4.

Step 7: The results of the aggregate probability are multiplied by the payment to each supplier in a state of nature $\left(\operatorname{Pr}_{i} \mathrm{~S}_{\mathrm{j}}\right)$, and the sum is divided by the number of arguments raised to the ratio of $1 /(r+q)$. In the situation of Provider 1, see Appendix A.5.

The B-PO denotation was previously given in this document and is a constituent part of the B-POWA.

Step 8: Consider for example that the decision-maker has set a value of $\beta=0.6$. With this parameter and the information of the B-OWA and the B-PO, it is possible to calculate the B-POWA.

For the proposed example, the calculation of the B-POWA for Provider 1 and the total for others, see Appendix A.6.

Step 9: With the above information, the suppliers can be ranked in descending order, where the first position corresponds to the most preferred alternative in the decision to purchase the agricultural input. The order is as follows:

$$
\operatorname{Pr}_{1}>\operatorname{Pr}_{3}>\operatorname{Pr}_{2}>\operatorname{Pr}_{4}
$$




\section{B-POWA Application in Forecasting the Price of Corn}

Corn is one of the most important agricultural products in the world. According to the FAO [10], it is mainly used for consumption by humans and as livestock feed. The Agri-food and Fisheries Information Service (SIAP) adds other uses, such as biofuel production, and it is an ingredient in the production of more than 4000 items.

The corn price varies over time due to different factors, such as quality, delivery times, interest rates, location, and seasonality; for this reason, knowledge of the behavior of future prices is vital for market participants [52].

The Chicago Mercantile Exchange (CME) issues information on the cash price and different futures contracts for commodities each day. Futures contracts use an estimated price depending on the conditions of the market on the day of purchase, but the price is always changing and is significantly volatile until the expiration date; for this reason, the use of different models to forecast the price with a lower error is a benefit of all market participants [53].

In this context, different investigations have been carried out using statistical models for price estimation that provide accurate information for decision-makers [54]. In 1990, Pindyck and Rotemberg [55] made material price forecasts using simple linear regression; [5] used the self-regressive vector methodology (VAR). On the other hand, Lieberman and Phillips [56] apply time series; however, Clinton and Lewis [15] comment that these techniques only take into account historical information without considering the information and expectations of experts.

This paper presents a new formulation to estimate the price of corn that considers the probability of an event occurring and the considerations of experts. The application of the formula is developed below. The data shown in Step 1 are the spot prices of futures, taking into account the maturity periods (March, May, July, September, and December).

Step 1: The payment table is constructed for the expensive period prices (See Table 2).

Table 2. Payment table ${ }^{1}$.

\begin{tabular}{cccccc}
\hline & S1 & S2 & S3 & S4 & S5 \\
\hline P1 Sep' 19 & 336 & 374 & 367 & 369 & 470 \\
P2 Jul' 19 & 336 & 336 & 374 & 367 & 369 \\
P3 May' 19 & 392 & 336 & 336 & 374 & 367 \\
P4 Mar' 19 & 367 & 392 & 336 & 336 & 374 \\
\hline
\end{tabular}

${ }^{1}$ The information was obtained in 15 August 2018 through the Chicago Mercantile Exchange (CME) webpage.

Step 2: Based on the assessment given by experts, as well as known information from previous events, weight vectors are determined $W_{i}=\{0.15,0.05,0.05,0.2,0.55\}$ and probability $P_{i}=\{0.1,0.2,0.2,0.05,0.45\}$ for the states of nature $S=\left\{S_{1}, S_{2}, S_{3}, S_{4}, S_{5}\right\}$, respectively.

Step 3: Vectors $V^{i}$ are established that allow us to calculate $O W A_{W}$ for $a_{j} \neq a_{i}$.

$$
\begin{aligned}
& \left(\operatorname{Pr}_{1} \mathrm{~S}_{1}\right)=\{374,367,369,470\},\left(\operatorname{Pr}_{1} \mathrm{~S}_{2}\right)=\{336,367,369,470\} \\
& \left(\operatorname{Pr}_{1} \mathrm{~S}_{3}\right)=\{336,374,369,470\},\left(\operatorname{Pr}_{1} \mathrm{~S}_{4}\right)=\{336,374,367,470\} \\
& \left(\operatorname{Pr}_{1} \mathrm{~S}_{5}\right)=\{336,374,367,369\},\left(\operatorname{Pr}_{2} \mathrm{~S}_{1}\right)=\{336,374,367,369\} \\
& \left(\operatorname{Pr}_{2} \mathrm{~S}_{2}\right)=\{336,374,367,369\},\left(\operatorname{Pr}_{2} \mathrm{~S}_{3}\right)=\{336,336,367,369\} \\
& \left(\operatorname{Pr}_{2} \mathrm{~S}_{4}\right)=\{336,336,374,369\},\left(\operatorname{Pr}_{2} \mathrm{~S}_{5}\right)=\{336,336,374,367\} \\
& \left(\operatorname{Pr}_{3} \mathrm{~S}_{1}\right)=\{336,336,374,367\},\left(\operatorname{Pr}_{3} \mathrm{~S}_{2}\right)=\{392,336,374,367\} \\
& \left(\operatorname{Pr}_{3} \mathrm{~S}_{3}\right)=\{392,336,374,367\},\left(\operatorname{Pr}_{3} \mathrm{~S}_{4}\right)=\{392,336,336,367\} \\
& \left(\operatorname{Pr}_{3} \mathrm{~S}_{5}\right)=\{392,336,336,374\},\left(\operatorname{Pr}_{4} \mathrm{~S}_{1}\right)=\{392,336,336,374\} \\
& \left(\operatorname{Pr}_{4} \mathrm{~S}_{2}\right)=\{367,336,336,374\},\left(\operatorname{Pr}_{4} \mathrm{~S}_{3}\right)=\{367,392,336,374\} \\
& \left(\operatorname{Pr}_{4} \mathrm{~S}_{4}\right)=\{367,392,336,374\},\left(\operatorname{Pr}_{4} \mathrm{~S}_{5}\right)=\{367,392,336,336\}
\end{aligned}
$$


Step 4: With the vectors $V^{i}$ for all proceeds, we proceed to calculate the value of $O W A_{W}\left(V^{i}\right)$ from the exclusive alternatives of $a_{i}$ multiplied by the weight vector $W$, as follows (See Table 3 ):

Table 3. Results of the ordered weighted averaging (OWA).

\begin{tabular}{cccccc}
\hline \multicolumn{5}{c}{ OWAw(PiSj) } \\
\hline & S1 & S2 & S3 & S4 & S5 \\
\hline P1 & 369 & 401 & 401 & 346 & 161 \\
P2 & 312 & 345 & 343 & 289 & 159 \\
P3 & 310 & 352 & 352 & 294 & 167 \\
P4 & 309 & 345 & 348 & 297 & 159 \\
\hline
\end{tabular}

Step 5: The previous results are multiplied by the payment of each price in a state of nature $\left(\operatorname{Pr}_{\mathrm{i}} \mathrm{S}_{\mathrm{j}}\right)$, and the sum is divided by the number of arguments and raised to the quotient between 1 and the sum of $r$ and $q$ (See Table 4).

Table 4. Results of the Bonferroni ordered weighted average (B-OWA).

\begin{tabular}{cc}
\hline \multicolumn{2}{c}{ B-OWAw(PiSj) } \\
\hline P1 & 353 \\
P2 & 320 \\
P3 & 325 \\
P4 & 324 \\
\hline
\end{tabular}

Step 6: To complete the calculation of the B-POWA, it is necessary to determine the value of the added probability $\mathrm{PA}_{\mathrm{W}_{\mathrm{j}}}$, obtained from the multiplication of the vector $\mathrm{V}^{\mathrm{i}}$ by the probability $\mathrm{p}_{\mathrm{j}}$ ordered according to $b_{j}$ (See Table 5).

Table 5. Data to calculate the Bonferroni Probabilistic Operator (B-PO).

\begin{tabular}{cccccc}
\hline & \multicolumn{5}{c}{ PAwj } \\
\hline & S1 & S2 & S3 & S4 & S5 \\
\hline P1 & 378 & 337 & 338 & 393 & 200 \\
P2 & 326 & 293 & 285 & 341 & 194 \\
P3 & 318 & 290 & 290 & 339 & 192 \\
P4 & 331 & 289 & 300 & 351 & 199 \\
\hline
\end{tabular}

Step 7: The results of the aggregate probability are multiplied by the payment of each price in a state of nature $\left(\operatorname{Pr}_{\mathrm{i}} \mathrm{S}_{\mathrm{j}}\right)$, and the sum is divided by the number of arguments raised to the ratio of $1 /(\mathrm{r}+\mathrm{q})$ (See Table 6).

Table 6. B-PO Results.

\begin{tabular}{lr}
\hline \multicolumn{2}{c}{ B-POwj } \\
\hline P1 & 351 \\
P2 & 320 \\
P3 & 322 \\
P4 & 325 \\
\hline
\end{tabular}

Step 8: Consider for example that the decision-maker has set a value of $\beta=0.6$. With this parameter and the information of the B-OWA and the B-PO, it is possible to calculate the B-POWA. 
In the result obtained in Table 7, it can be seen that with the new B-POWA formulation, which accounts for different information offered by the decision-maker, the forecast error has been reduced, comparing the spot price with the future published by the CME and the amount calculated with the formulation proposed in this paper. All the periods show reduced errors.

Table 7. Results of the Bonferroni probabilistic ordered weighted average (B-POWA).

\begin{tabular}{cccccc}
\hline & B-POWA(PjSj) & Future CME & Spot & CME vs. Spot & B-POWA vs. Spot \\
\hline P1 & 352 & 399 & 369 & 30 & 17 \\
P2 & 320 & 401 & 336 & 65 & 16 \\
P3 & 324 & 393 & 349 & 44 & 25 \\
P4 & 324 & 392 & 354 & 38 & 30 \\
\hline
\end{tabular}

It is important to note that the results obtained in the present application are highly influenced by the values obtained by the experts/decision-makers with the weighting and probability vectors. This is one of the main limitations of this kind of methodology, which uses information provided by the users and is therefore subjective, as is their contribution. These types of operators are characterized as presenting different scenarios based on the profile of the decision-maker; for example, in finance it is common that some people will not buy some assets if they find it risky. However, others will buy them-the decision is not based on the results that the specific asset will have but instead of the aversion of risk that the investor has. The same is applied to this type of problem; imagine a farmer who wants to know the future price of corn to decide whether to sow corn or not. With traditional formulations, the historical information will provide the answer but maybe because of the volatility of the price the farmer, by the values of the weighting and probability vector, farmer can make different scenarios based on various factors that he believes will impact the price such as weather, storage, competition, government policy, planting support and many more to obtain a result based on their expectations and finally make a decision on whether to plant corn or not.

As can be seen with the results obtained in Table 7, the B-POWA operator can be used to make new scenarios in uncertainty through the use of a vector $\mathrm{V}^{\mathrm{i}}$ that intercorrelate the arguments and also use a weighting vector and probability vector that include the expectation and attitude of the decision-maker to the problem. These two characteristics are important because many real world problems can be addressed with these type of operators, as has been seen through behavioral economics [57] and behavioral finance [58], as the decisions that are made in different sectors are not only based on historical and statistical data but should include some qualitative information that the decision-maker has and that is the main attribute of the B-POWA operator.

Among the main benefits of using the probabilistic uncertainty theory to forecast the price of agricultural models is that there are some elements that affect the price that is related to probabilities, such as the case of the weather, i.e., the news about it is based on the probability of being a rainy, cloudy or sunny season. In this kind of case, the probabilities adjust better to the expectations of the future. It is important to note that other uncertainty theories can be used depending on the case that wants to be analyzed, such as the case of rough numbers that have been used in different problems such as the evaluation of logistic providers [59], healthcare waste disposal locations [60], location selection for a construction [61], and many more.

\section{Conclusions}

Uncertainty in financial markets has been characterized by the irrationality of decision-makers and the sudden changes in situations that were considered stable [62], with agricultural products not being the exception. Thus, questions regarding what to sow and how much to sow become more complex. It is derived from the fact that at the beginning of planting, the price is one figure, and when the harvest is made, it becomes a very different figure. In this sense, it is necessary to use different techniques and models that can be adapted to the volatility of the prices and uncertainty of the market $[63,64]-$ such 
tools can be the aggregation operators, and this field has been expanded through different techniques and applications [18].

The objective of the present paper is to present the Bonferroni probabilistic ordered weighted average (B-POWA) operator and its application to decision-making based on price estimations for agricultural commodities. Some characteristics, special cases and extensions are also studied in the paper. Furthermore, a mathematical example is provided to visualize the characteristic properties of the proposed operator. Finally, methodological applications to the price estimation of corn that compares the performance of the B-POWA operator and other traditional methods is addressed.

Accurate price analyses and forecasting results are vital in the agricultural sector, and the ability to obtain them has implications on fair trade for farmers and the creation and establishment of economic policies for nations. On the long list of commodities traded in global markets, corn is one of the most important due to its several usages and relevance in human and livestock nutrition. Therefore, an accurate forecasting of corn prices would have positive effects for diverse stakeholders. However, this task is highly complex because of the intrinsically uncertain nature and volatility of the markets. Thus, the creation of different tools is highly recommended.

The characteristic mechanism of the B-POWA operator, derived from intelligent and expert systems [65], makes it an interesting tool for the assessment of price forecasting. The results of the application of the mechanism of price estimation, considering probabilistic information, along with the expectations of diverse experts, reveal that it performs better than traditional methods. The proposed operator shows diverse arrangements for the selected periods of time and contrasting information on the given states of nature. These results help the decision-maker understand the complexity of the market and adopt alternatives that offer less risk to a company in maximizing its profits. The main advantage that the use of the B-POWA operator has over the traditional OWA or POWA operator is that, with the incorporation of the Bonferroni method, it is possible to make an interrelation between the arguments of the means in the same formulation by using vectors $\mathrm{V}^{\mathrm{i}}$ instead of the value of the argument that the OWA and POWA operators use. Additionally, it is important to note that this operator can be used for different problems in finance and economics, where some of the results are related to the probabilities of events/elements that occur, such as the sales, costs, exchange rate, inflation, market share and other related cases.

Further research is required to address some of the limitations of the present study, e.g., the inclusion of other extensions for the further representation of complex phenomena such as induced vectors (when the arguments are arranged based on induced values instead of the value of the argument) [66], logarithmic functions (to reduce skewness towards large values) [21], heavy weighting vectors (when the weighting vector is not equal to 1) [67], geometric operators (when the problem to be analyzed uses numbers that are multiplied together) [68], linguistic OWA operators (when the arguments are linguistic variables and not numbers) [69] and others related to the decision-making process. The inclusion of these tools supports the general purpose of this research, namely, to shed light on the development of new approaches for the accurate assessment of pricing models and reliable forecasting by the fusion of several sources of information

Additionally, the problems can be addressed by including more elements of the fuzzy logic approach to avoid the unnecessary rigidities; such is the case of fuzzy sets [70], fuzzy numbers [71], and many more of the extensions of different techniques based on fuzzy logic theory [72]. The use of different uncertainty theories is important to include and propose solutions to new real problems in different fields like economics, finance, and engineering [73].

Author Contributions: The contribution for each author is the following: conceptualization, M.O.-L.; methodology, L.F.E.-A.; validation, F.B.-M.; formal analysis, E.L.-C.; project administration, V.A.-G. All authors have read and agreed to the published version of the manuscript.

Funding: This research was funded by FONDECYT initiation grant No. 11190056. 
Conflicts of Interest: The authors declare no conflict of interest. The funders had no role in the design of the study; in the collection, analyses, or interpretation of data; in the writing of the manuscript, or in the decision to publish the results.

\section{Appendix A}

Appendix A.1 Calculation of $\operatorname{Pr}_{i} S_{j}$ Pairs for Provider 1

$$
\begin{gathered}
\left(\operatorname{Pr}_{1} S_{1}\right)=\{85,80,78,60\},\left(\operatorname{Pr}_{1} S_{2}\right)=\{90,80,78,60\},\left(\operatorname{Pr}_{1} S_{3}\right)=\{90,85,78,60\} \\
\left(\operatorname{Pr}_{1} S_{4}\right)=\{90,85,80,60\},\left(\operatorname{Pr}_{1} S_{5}\right)=\{90,85,80,78\}
\end{gathered}
$$

Appendix A.2 Calculation of OWA $A_{W}$ for $\mathrm{Pr}_{1} S_{j}$ for Provider 1

$$
\begin{gathered}
\mathrm{OWA}_{\mathrm{W}}\left(\operatorname{Pr}_{1} \mathrm{~S}_{1}\right)=(0.25 * 85)+(0.15 * 80)+(0.2 * 78)+(0.1 * 60)=54.85 \\
\mathrm{OWA}_{\mathrm{W}}\left(\operatorname{Pr}_{1} \mathrm{~S}_{2}\right)=(0.3 * 90)+(0.15 * 80)+(0.2 * 78)+(0.1 * 60)=60.6 \\
\mathrm{OWA}_{\mathrm{W}}\left(\operatorname{Pr}_{1} \mathrm{~S}_{2}\right)=(0.3 * 90)+(0.15 * 80)+(0.2 * 78)+(0.1 * 60)=60.6 \\
\mathrm{OWA}_{\mathrm{W}}\left(\operatorname{Pr}_{1} S_{3}\right)=(0.3 * 90)+(0.25 * 85)+(0.2 * 78)+(0.1 * 60)=69.85 \\
\mathrm{OWA}_{\mathrm{W}}\left(\operatorname{Pr}_{1} \mathrm{~S}_{4}\right)=(0.3 * 90)+(0.25 * 85)+(0.15 * 80)+(0.1 * 60)=66.25 \\
\mathrm{OWA}_{\mathrm{W}}\left(\operatorname{Pr}_{1} S_{5}\right)=(0.3 * 90)+(0.25 * 85)+(0.15 * 80)+(0.2 * 78)=75.85
\end{gathered}
$$

Appendix A.3 Calculation of B-OWA Operator for Provider 1

$$
\begin{gathered}
\text { BON }-\mathrm{OWA}\left(\operatorname{Pr}_{1} \mathrm{~S}_{1}, \ldots, \mathrm{Pr}_{1} \mathrm{~S}_{5}\right) \\
=\left(\frac{(90 * 54.85)+(85 * 60.6)+(80 * 69.85)+(78 * 66.25)+(60 * 75.85)}{5}\right)^{\frac{1}{2}} \\
\text { BON - OWA }\left(\operatorname{Pr}_{1} S_{1}, \ldots, \operatorname{Pr}_{1} S_{5}\right)=\left(\frac{25394}{5}\right)^{\frac{1}{2}}=71.26
\end{gathered}
$$

Appendix A.4 Calculation of PA $A_{W}$ for Provider 1

$$
\begin{aligned}
& \operatorname{PA}_{W}\left(\operatorname{Pr}_{1} S_{1}\right)=(0.2 * 85)+(0.4 * 80)+(0.2 * 78)+(0.1 * 60)=70.6 \\
& \operatorname{PA}_{W}\left(\operatorname{Pr}_{1} S_{2}\right)=(0.1 * 90)+(0.4 * 80)+(0.2 * 78)+(0.1 * 60)=62.6 \\
& \operatorname{PA}_{W}\left(\operatorname{Pr}_{1} S_{3}\right)=(0.1 * 90)+(0.2 * 85)+(0.2 * 78)+(0.1 * 60)=47.6 \\
& \operatorname{PA}_{W}\left(\operatorname{Pr}_{1} S_{4}\right)=(0.1 * 90)+(0.2 * 85)+(0.4 * 80)+(0.1 * 60)=64 \\
& \operatorname{PA}_{W}\left(\operatorname{Pr}_{1} S_{5}\right)=(0.1 * 90)+(0.2 * 85)+(0.4 * 80)+(0.2 * 78)=73.6
\end{aligned}
$$

Appendix A.5 Calculation of the B-PO Operator for Provider 1

$$
\begin{gathered}
\mathrm{BON}-\mathrm{PO}\left(\operatorname{Pr}_{1} \mathrm{~S}_{1}, \ldots, \mathrm{Pr}_{1} \mathrm{~S}_{5}\right)=\left(\frac{(90 * 70.6)+(85 * 62.6)+(80 * 47.6)+(78 * 64)+(60 * 73.6)}{5}\right)^{\frac{1}{2}} \\
\mathrm{BON}-\mathrm{PO}\left(\operatorname{Pr}_{1} \mathrm{~S}_{1}, \ldots, \operatorname{Pr}_{1} \mathrm{~S}_{5}\right)=\left(\frac{24891}{5}\right)^{\frac{1}{2}}=70.55
\end{gathered}
$$

Appendix A.6 Calculation of B-POWA Operator for Provider 1

$$
\begin{gathered}
\text { BON - POWA }\left(\operatorname{Pr}_{1} S_{1}, \ldots, \operatorname{Pr}_{1} S_{5}\right)=(0.6 * 71.26)+((1-0.6) * 70.55)=70.98 \\
\text { BON-POWA }\left(\operatorname{Pr}_{2} S_{1}, \ldots, \operatorname{Pr}_{2} S_{5}\right)=54.98 \\
\text { BON-POWA }\left(\operatorname{Pr}_{3} S_{1}, \ldots, \operatorname{Pr}_{3} S_{5}\right)=63.9 \\
\text { BON-POWA }\left(\operatorname{Pr}_{4} S_{1}, \ldots, \operatorname{Pr}_{4} S_{5}\right)=47.45
\end{gathered}
$$




\section{References}

1. Brandt, J.A.; Bessler, D.A. Price forecasting and evaluation: An application in agriculture. J. Forecast. 1983, 2, 237-248. [CrossRef]

2. Pinheiro, C.A.; Senna, V. Multivariate analysis and neural networks application to price forecasting in the Brazilian agricultural market. Ciência Rural 2017, 47. [CrossRef]

3. Zhang, D.; Chen, S.; Liwen, L.; Xia, Q. Forecasting agricultural commodity prices using model selection framework with time series features and forecast horizons. IEEE Access 2020, 8, 28197-28209. [CrossRef]

4. Cárcamo, U.C.; Ceballos, L.E.F. Una aproximación a la estimación de rendimientos de conveniencia y precios teóricos de futuros para commodities agropecuarios en Colombia. Cuad. Adm. 2012, 25, 141-173.

5. Xiong, T.; Li, C.; Bao, Y.; Hu, Z.; Zhang, L. A combination method for interval forecasting of agricultural commodity futures prices. Knowl. -Based Syst. 2015, 77, 92-102. [CrossRef]

6. Chernov, M.; Ronald Gallant, A.; Ghysels, E.; Tauchen, G. Alternative models for stock price dynamics. J. Econom. 2003, 116, 225-257. [CrossRef]

7. Asturias, M.A. Maíz de Alimento Sagrado a Negocio del Hambre; Acción Ecológica; Red para una América Latina Libre de Transgénicos: Quito, Ecuador, 2004.

8. UNFAO. The state of food and agriculture: Moving forward on food loss and waste reduction. In The State of the World; FAO, Global: Rome, Italy, 2019.

9. González Merino, A.; Ávila Castañeda, J.F. El maíz en Estados Unidos y en México. Hegemonía en la producción de un cultivo. Argumentos 2014, 27, 215-235.

10. Just, R.E.; Rausser, G.C. Commodity price forecasting with large-scale econometric models and the futures market. Am. J. Agric. Econ. 1981, 63, 197-208. [CrossRef]

11. Wang, R. Research on the application of the financial investment risk appraisal models with some interval number muirhead mean operators. J. Intell. Fuzzy Syst. 2019, 37, 1741-1752. [CrossRef]

12. Ge, Y.; Wu, H. Prediction of corn price fluctuation based on multiple linear regression analysis model under big data. Neural Comput. Appl. 2019. [CrossRef]

13. Peng, Y.; Hsu, C.; Huang, P. Developing Crop Price Forecasting Service Using Open Data from Taiwan Markets. In Proceedings of the 2015 Conference on Technologies and Applications of Artificial Intelligence (TAAI), Tainan, Taiwan, 20-22 November 2015; pp. 172-175.

14. Shahwan, T.; Odening, M. Forecasting Agricultural Commodity Prices Using Hybrid Neural Networks. In Computational Intelligence in Economics and Finance; Springer: Berlin/Heidelberg, Germany, 2007; pp. 63-74.

15. Clinton, J.D.; Lewis, D.E. Expert opinion, agency characteristics, and agency preferences. Political Anal. 2008, 16, 3-20. [CrossRef]

16. Torra, V.; Narukawa, Y. Modeling Decisions; Cognitive Technologies Springer: Berlin/Heidelberg, Germany, 2007.

17. Yager, R.R. On ordered weighted averaging aggregation operators in multicriteria decision-making. IEEE Trans. Syst. Man Cybern. 1988, 18, 183-190. [CrossRef]

18. Blanco-Mesa, F.; León-Castro, E.; Merigó, J.M. A bibliometric analysis of aggregation operators. Appl. Soft Comput. 2019, 81, 105488. [CrossRef]

19. Zhou, L.; Chen, H. Generalized ordered weighted logarithm aggregation operators and their applications to group decision making. Int. J. Intell. Syst. 2010, 25, 683-707. [CrossRef]

20. Alfaro-García, V.G.; Merigó, J.M.; Gil-Lafuente, A.M.; Kacprzyk, J. Logarithmic aggregation operators and distance measures. Int. J. Intell. Syst. 2018, 33, 1488-1506. [CrossRef]

21. Alfaro-García, V.G.; Merigó, J.M.; Plata-Pérez, L.; Alfaro-Calderón, G.G.; Gil-Lafuente, A.M. Induced and logarithmic distances with multi-region aggregation operators. Technol. Econ. Dev. Econ. 2019, 25, 1-29. [CrossRef]

22. León-Castro, E.; Avilés-Ochoa, E.; Merigó, J.M. Induced Heavy Moving Averages. Int. J. Intell. Syst. 2018, 33, 1823-1839. [CrossRef]

23. León-Castro, E.; Avilés-Ochoa, E.; Merigó, J.M.; Gil-Lafuente, A.M. Heavy moving averages and their application in econometric forecasting. Cybern. Syst. 2018, 49, 26-43. [CrossRef]

24. Olazabal-Lugo, M.; León-Castro, E.; Espinoza-Audelo, L.F.; Merigó, J.M.; Gil-Lafuente, A.M. Forgotten effects and heavy moving averages in exchange rate forecasting. Econ. Comput. Econ. Cybern. Stud. Res. 2019, 53, 79-96. 
25. Blanco-Mesa, F.; Merigó, J.M.; Kacprzyk, J. Bonferroni means with distance measures and the adequacy coefficient in entrepreneurial group theory. Knowl. Based Syst. 2016, 111, 217-227. [CrossRef]

26. Yager, R.R. On generalized Bonferroni mean operators for multicriteria aggregation. Int. J. Approx. Reason. 2009, 50, 1279-1286. [CrossRef]

27. Li, X.; Chen, X. Multi-criteria group decision making based on trapezoidal intuitionistic fuzzy information. Appl. Soft Comput. 2015, 30, 454-461. [CrossRef]

28. Merigó, J.M.; Peris-Ortíz, M.; Navarro-García, A.; Rueda-Armengot, C. Aggregation operators in economic growth analysis and entrepreneurial group decision-making. Appl. Soft Comput. J. 2016, 47, 141-150. [CrossRef]

29. Merigó, J.M.; Casanovas, M. Decision-making with distance measures and induced aggregation operators. Comput. Ind. Eng. 2011, 60, 66-76. [CrossRef]

30. Wang, L.; Feng, J.; Sui, X.; Chu, X.; Mu, W. Agricultural product price forecasting methods: Research advances and trend. Br. Food J. 2020, 122, 2121-2138. [CrossRef]

31. Avilés-Ochoa, E.; Perez-Arellano, L.A.; León-Castro, E.; Merigó, J.M. Prioritized induced probabilistic distances in transparency and access to information laws. Fuzzy Econ. Rev. 2017, 22, 45-55. [CrossRef]

32. Pérez-Arellano, L.A.; León-Castro, E.; Avilés-Ochoa, E.; Merigó, J.M. Prioritized induced probabilistic operator and its application in group decision making. Int. J. Mach. Learn. Cybern. 2019, 10, 451-462.

33. Blanco-Mesa, F.; Merigó, J.M. Bonferroni distance with hybrid weighted distance and immediate weighted distance. Fuzzy Econ. Rev. 2017, 22, 29-43. [CrossRef]

34. Blanco-Mesa, F.; Merigó, J.M. Bonferroni distances and their application in group decision making. Cybern. Syst. 2020, 51, 27-58. [CrossRef]

35. Blanco-Mesa, F.; León-Castro, E.; Merigó, J.M. Bonferroni induced heavy operators in ERM decision-making: A case on large companies in Colombia. Appl. Soft Comput. 2018, 72, 371-391. [CrossRef]

36. Blanco-Mesa, F.; León-Castro, E.; Merigó, J.M.; Xu, Z.S. Bonferroni means with induced ordered weighted average operators. Int. J. Intell. Syst. 2019, 34, 3-23. [CrossRef]

37. Blanco-Mesa, F.; León-Castro, E.; Merigó, J.M. Covariances with OWA operators and Bonferroni means. Soft Comput. 2020, 1-16. [CrossRef]

38. Blanco-Mesa, F.; León-Castro, E.; Merigó, J.M.; Herrera-Viedma, E. Variances with Bonferroni means and ordered weighted averages. Int. J. Intell. Syst. 2019, 34, 3020-3045. [CrossRef]

39. Bonferroni, C. Sulle medie multiple di potenze. Boll. Dell'Unione Mat. Ital. 1950, 5, 267-270.

40. Merigó, J.M. Probabilities in the OWA operator. Expert Syst. Appl. 2012, 39, 11456-11467. [CrossRef]

41. Engemann, K.J.; Filev, D.P.; Yager, R.R. Modelling decision making using immediate probabilities. Int. J. Gen. Syst. 1996, 24, 281-294. [CrossRef]

42. Bland, J.M.; Altman, D.G. Statistics notes: Multiple significance tests: The Bonferroni method. Br. Med. J. 1995, 310, 310. [CrossRef]

43. Narum, S.R. Beyond Bonferroni: Less conservative analyses for conservation genetics. Conserv. Genet. 2006, 7, 783-787. [CrossRef]

44. Bolelli, G.; Bonferroni, B.; Laurila, J.; Lusvarghi, L.; Milanti, A.; Niemi, K.; Vuoristo, P. Micromechanical properties and sliding wear behaviour of HVOF-sprayed Fe-based alloy coatings. Wear 2012, 276-277, $29-47$. [CrossRef]

45. Xu, Z.S. An overview of methods for determining OWA weights. Int. J. Intell. Syst. 2005, 20, 843-865. [CrossRef]

46. Merigó, J.M.; Casanovas, M. Induced aggregation operators in the Euclidean distance and its application in financial decision making. Expert Syst. Appl. 2011, 38, 7603-7608. [CrossRef]

47. Yager, R.R. Quantifier guided aggregation using OWA operators. Int. J. Intell. Syst. 1998, 11, 49-73. [CrossRef]

48. Blanco-Mesa, F.; León Castro, E.; Gil-Lafuente, A.M. Aplicaciones Matemáticas para la toma de Decisiones Empresariales en Entornos Inciertos; Vallespín Pérez, D., Ed.; Juruá Editorial: Porto, Portugal, 2019; ISBN 9789897125911.

49. Yager, R.R. Constrained OWA aggregation. Fuzzy Sets Syst. 1996, 81, 89-101. [CrossRef]

50. Merigó, J.M. OWA operators in the weighted average and their application in decision making. Control Cybern. 2012, 41, 605-643.

51. Blanco-Mesa, F.; Merigó, J.M.; Gil-Lafuente, A.M. Fuzzy decision making: A bibliometric-based review. J. Intell. Fuzzy Syst. 2017, 32, 2033-2050. [CrossRef] 
52. Hoffman, L. Longitudinal Analysis: Modeling within-Person Fluctuation and Change; Routledge: New York, NY, USA; London, UK, 2015; ISBN 9788578110796.

53. Saavedra, G.M.; Urtilla, A.J. Evolución y análisis del mercado de derivados en México. Argumentos 2009, 22, 285-311.

54. Chiang, I.H.E.; Hughen, W.K.; Sagi, J.S. Estimating oil risk factors using information from equity and derivatives markets. J. Financ. 2015, 70, 769-804. [CrossRef]

55. Pindyck, R.S.; Rotemberg, J.J. The excess co-movement of commodity prices. Econ. J. 1990, 100, 1173. [CrossRef]

56. Lieberman, O.; Phillips, P.C.B. Refined inference on long memory in realized volatility. Econom. Rev. 2008, 27, 254-267. [CrossRef]

57. Mullainathan, S.; Thaler, R.H. Behavioral Economics; National Bureau of Economic Research: Cambridge, MA, USA, 2000.

58. Ritter, J.R. Behavioral finance. Pac.-Basin Financ. J. 2003, 11, 429-437. [CrossRef]

59. Sinani, F.; Erceg, Ž.; Vasiljević, M. An evaluation of a third-party logistics provider: The application of the rough Dombi-Hamy mean operator. Decis. Mak. Appl. Manag. Eng. 2020, 3, 92-107.

60. Yazdani, M.; Tavana, M.; Pamučar, D.; Chatterjee, P. A rough based multicriteria evaluation method for healthcare waste disposal location decisions. Comput. Ind. Eng. 2020, 143, 106394. [CrossRef]

61. Stević, Ž.; Pamučar, D.; Subotić, M.; Antuchevičiene, J.; Zavadskas, E.K. The location selection for roundabout construction using Rough BWM-Rough WASPAS approach based on a new Rough Hamy aggregator. Sustainability 2018, 10, 2817. [CrossRef]

62. Singh, S. Investor irrationality and self-defeating behavior: Insights from behavioral finance. J. Glob. Bus. Manag. 2012, 8, 116.

63. Jarrett, U.; Mohaddes, K.; Mohtadi, H. Oil price volatility, financial institutions and economic growth. Energy Policy 2019, 126, 131-144. [CrossRef]

64. Sadik-Zada, E.R.; Loewenstein, W.; Hasanli, Y. Commodity revenues, agricultural sector and the magnitude of deindustrialization: A novel multisector perspective. Economies 2019, 7, 113. [CrossRef]

65. Beliakov, G.; Pradera, A.; Calvo, T. Aggregation Functions: A Guide for Practitioners. In Studies in Fuzziness and Soft Computing; Springer: Berlin/Heidelberg, Germany, 2007; Volume 221, ISBN 978-3-540-73720-93.

66. Yager, R.R.; Filev, D.P. Induced ordered weighted averaging operators. IEEE Trans. Syst. Man Cybern. Part B Cybern. 1999, 29, 141-150.

67. León-Castro, E.; Espinoza-Audelo, L.F.; Merigó, J.M.; Gil-Lafuente, A.M.; Yager, R.R. The ordered weighted average inflation. J. Intell. Fuzzy Syst. 2020, 38, 1901-1913. [CrossRef]

68. Xu, Z.S.; Da, Q.L. The ordered weighted geometric averaging operators. Int. J. Intell. Syst. 2002, 17, 709-716. [CrossRef]

69. Chiclana, F.; Mata, F.; Pérez, L.G.; Herrera-Viedma, E. Type-1 OWA Unbalanced Fuzzy Linguistic Aggregation Methodology: Application to EuroBds Credit Risk Evaluation. Int. J. Intell. Syst. 2018, 33, 1071-1088. [CrossRef]

70. Zadeh, L.A. Fuzzy sets. Inf. Control 1965, 8, 338-353. [CrossRef]

71. Dubois, D.; Prade, H. Operations on fuzzy numbers. Int. J. Syst. Sci. 1978, 9, 613-626. [CrossRef]

72. Merigó, J.M.; Gil-Lafuente, A.M.; Yager, R.R. An overview of fuzzy research with bibliometric indicators. Appl. Soft Comput. 2015, 27, 420-433. [CrossRef]

73. Sadik-Zada, E.R. Distributional Bargaining and the Speed of Structural Change in the Petroleum Exporting Labor Surplus Economies. Eur. J. Dev. Res. 2020, 32, 51-98. [CrossRef]

(C) 2020 by the authors. Licensee MDPI, Basel, Switzerland. This article is an open access article distributed under the terms and conditions of the Creative Commons Attribution (CC BY) license (http://creativecommons.org/licenses/by/4.0/). 